\title{
Editorial
}

\section{Time for leadership development interventions in the public health nutrition workforce}

Much has been written about the importance of leadership in driving change, achieving organisational objectives and facilitating appropriate responses to public health or other challenges. We regularly hear commentators and politicians argue that strong leadership is needed, particularly in tough times such as during conflicts, economic meltdowns or flu pandemics. What leadership actually means, what competencies are required to be a leader and what role the application of leadership plays in successfully responding to challenges, are however unclear in this dialogue. These questions are relevant to the development of public health nutrition as a discipline and as a profession.

\section{What is leadership?}

Leadership has a range of definitions, but at its simplest it is concerned with the ability to influence others to achieve goals. The process and attributes required to effectively influence others are central to an understanding of leadership and its currency in the context of developing public health nutrition as a discipline and its place in our daily practice. There is an established literature that describes the personal attributes of leaders ${ }^{(1)}$, including having a big picture vision that is effectively shared and decision making that is clear and decisive based on assessment of available information. Leaders have a commitment to capacity building and empowering others, are respectful and consultative but willing to make tough decisions when required. At the core of leadership is the attribute of credibility, usually earned by demonstrated ethical and transparent approaches to practice. Leaders take calculated risks when required, speak out against the status quo and step forward to take responsibility and show initiative when needed. This type of behaviour in practice requires good strategic thinking, interpersonal communication skills and emotional intelligence. In reality we all show and need leadership skills to be effective in our daily practice, whether that be in academia, communities or organisations. We all work to influence others to achieve our objectives, irrespective of the level at which we operate in society. Leadership is not confined to the top of the decision-making tree, but instead is often required at lower-down levels to 'shake the branches'.

\section{Leadership development required}

At a professional level there is a need for strategic development initiatives that build leadership within the public health nutrition workforce. Leadership is not an innate characteristic, but a complex suite of competencies, personal attributes and vision that requires development via education, exposure to work and issues, role modelling and mentoring with existing leaders. The need for workforce leadership development as a strategic intervention is accentuated when there is an under-developed workforce infrastructure characterised by a limited number of mentors and workforce disorganisation. This describes the public health nutrition workforce in most parts of the world. The importance of leadership development as a workforce development intervention has been recognised by the food industry in Europe in the form of the European Nutrition Leadership Programme since the mid-1990s, and has been replicated in various forms in other parts of the world since then.

\section{Time for strategic action}

Spontaneous leadership development within the workforce is a slow and unresponsive process that necessitates strategic intervention. It is time that the public health nutrition community mobilised to develop the next generation of leaders in our students and early career colleagues, so that they can more effectively take on current and future public health nutrition challenges than we have. The biggest test of our existing leadership (read you and me) is how effectively we do this. This journal welcomes debate about how this can be achieved; so please, show some leadership, express an opinion via our letters section or submit a commentary, and have some influence.

Roger Hughes

Deputy Editor

\section{Reference}

1. Edmonstone J \& Western J (2002) Leadership development in health care: what do we know? J Manag Med 16, $34-47$. 